\title{
Formation of Benzyl Carbanion in Collision-Induced Dissociation of Deprotonated Phenylalanine Homologues
}

\author{
Kanako Sekimoto, Natsuki Matsuda, and Mitsuo Takayama* \\ Graduate School of Nanobioscience, Yokohama City University, 22-2 Seto, Kanazawa-ku, Yokohama, Kanagawa 236-0027, Japan
}

\begin{abstract}
The fragmentation behavior of deprotonated L-phenylalanine (Phe) and its homologues including Lhomophenylalanine (HPA) and L-phenylglycine (PG) was investigated using collision-induced dissociation mass spectrometry coupled with a negative ion atmospheric pressure corona discharge ionization (APCDI) technique. The deprotonated molecules $[\mathrm{M}-\mathrm{H}]^{-}$fragmented to lose unique neutral species, e.g., the loss of $\mathrm{NH}_{3}, \mathrm{CO}_{2}$, toluene and iminoglycine for $[\mathrm{Phe}-\mathrm{H}]^{-}$; styrene and ethenamine/CO $\mathrm{CO}_{2}$ for $[\mathrm{HA}-\mathrm{H}]^{-}$; and $\mathrm{CO}_{2}$ for $[\mathrm{PG}-\mathrm{H}]^{-}$. All of the fragmentations observed are attributable to the formation of intermediates and/or product ions which include benzyl carbanions having resonance-stabilized structures. The carbanions are formed via proton rearrangement through a transition state or via a simple dissociation reaction. These results suggest that the principal factor governing the fragmentation behavior of deprotonated Phe homologues is the stability of the intermediate and/or product ion structures.
\end{abstract}

Please cite this article as: K. Sekimoto, et al., Formation of Benzyl Carbanion in Collision-Induced Dissociation of Deprotonated Phenylalanine Homologues, Mass Spectrom (Tokyo) 2014; 3(1): A0027; DOI: 10.5702/massspectrometry.A0027

Keywords: collision-induced dissociation (CID), atmospheric pressure corona discharge ionization (APCDI), phenylalanine homologues, benzyl carbanion, fragmentation

(Received January 15, 2014; Accepted April 9, 2014)

\section{INTRODUCTION}

Amino acids are the critically important constitutive units of various organic macromolecules such as proteins. One of the most widespread techniques for amino acid analysis is based on chromatographic separation either following or preceding the derivatization of the amino acids with ultraviolet light absorptive or fluorescent functional group detection, ${ }^{1,2)}$ or ion-exchange chromatography. ${ }^{3)}$ Measurements of underivatized amino acids, in contrast, have been performed via mass spectrometry (MS) using various ionization techniques including electron ionization, ${ }^{4,5)}$ field desorption, ${ }^{6}$ chemical ionization, ${ }^{7-11)}$ fast atom bombardment, ${ }^{12,13)}$ electrospray ionization (ESI), ${ }^{14-18)}$ and atmospheric pressure chemical ionization (APCI).${ }^{19,20)}$ ESI and APCI, typical atmospheric pressure ionization techniques, have widely contributed to the success of liquid chromatography coupled to MS for the fast analysis of underivatized amino acid. ${ }^{14,16,17,19)}$ Collision-induced dissociation (CID) methods have been utilized in order to better understand the fragmentation behavior of (de)protonated amino acids $[\mathrm{M} \pm$ $\mathrm{H}]^{ \pm} \cdot{ }^{12-14,16,17,20)}$ It has been reported that CID of protonated $\alpha$-amino acids $[\mathrm{M}+\mathrm{H}]^{+}$can be interpreted simply by the loss of specific neutral species such as $\mathrm{NH}_{3}, \mathrm{H}_{2} \mathrm{O}$, and $\mathrm{CO}_{2} \mathrm{H}_{2}$ consisting of $\mathrm{CO}$ and $\mathrm{H}_{2} \mathrm{O}$, which depends on the various side chains. ${ }^{12)}$ On the other hand, deprotonated amino acids $[\mathrm{M}-\mathrm{H}]^{-}$fragment irregularly to lose $\mathrm{H}_{2}, \mathrm{NH}_{3}, \mathrm{H}_{2} \mathrm{O}, \mathrm{CO}_{2}$, and $\mathrm{CO}_{2} \mathrm{H}_{2}$, although the aliphatics retain a characteristic preference for $\mathrm{CO}_{2} \mathrm{H}_{2}$ loss. Thus, these previous reports have noted that $\alpha$-amino acids other than aliphatics cannot be classified according to specific neutral fragment loss in the CID of $[\mathrm{M}-\mathrm{H}]^{-} .{ }^{12)}$ In order to develop a more efficient MS method useful for amino acid analysis, it is necessary to discover the crucial factors governing the fragmentation behavior of deprotonated amino acids, and especially that of the non-aliphatic ones.

Herein is presented an investigation of the fragmentation behavior of L-phenylalanine (Phe) (an aromatic amino acid) and its homologues, L-homophenylalanine (HPA) and Lphenylglycine $(\mathrm{PG})$, using negative ion atmospheric pressure corona discharge ionization (APCDI) CID-MS. The analytes used have the same functionality involving phenyl, amino and carboxyl groups. The difference between Phe and HPA/ PG is simply the possession of one methylene unit more or less. While individual deprotonated molecules $[\mathrm{Phe}-\mathrm{H}]^{-}$, $[\mathrm{HPA}-\mathrm{H}]^{-}$, and $[\mathrm{PG}-\mathrm{H}]^{-}$dissociate to lose unique neutral species, all of the fragmentations observed can be attributed to the formation of benzyl carbanions as intermediates and/ or product ions. The formation of the benzyl carbanion may be a key structural element in the process of fragmenting deprotonated Phe homologues. This report discusses in detail the fragmentation behavior of $[\mathrm{Phe}-\mathrm{H}]^{-},[\mathrm{HPA}-\mathrm{H}]^{-}$, and $[\mathrm{PG}-\mathrm{H}]^{-}$involving the formation of benzyl carbanions.

* Correspondence to: Mitsuo Takayama, Graduate School of Nanobioscience, Yokohama City University, 22-2 Seto, Kanazawa-ku, Yokohama, Kanagawa 236-0027, Japan, e-mail: takayama@yokohama-cu.ac.jp 


\section{EXPERIMENTAL}

\section{Analytes}

L-Phenylalanine $\left(M_{r}\right.$ 165) was purchased from SigmaAldrich (Saint Louis, MO, USA). L-Homophenylalanine $\left(M_{r} 170\right)$ and L-phenylglycine $\left(M_{r} 151\right)$ were purchased from Tokyo Chemical Industry (Tokyo, Japan). The deuterium (D) labeled derivative of L-phenylalanine $\left(M_{r} 167\right)$, which has $2 \mathrm{D}$ atoms at the benzylic position, was purchased from Taiyo Nippon Sanso Corp. (Tokyo, Japan). All of the analytes were used without further purification.

\section{APCDI and CID-MS}

Discharge experiments using point-to-plane electrodes were performed at atmospheric pressure in unadulterated laboratory air, composed of common air constituents $\mathrm{N}_{2}$, $\mathrm{O}_{2}, \mathrm{H}_{2} \mathrm{O}$, and $\mathrm{CO}_{2}$. The laboratory temperature $(298 \mathrm{~K})$ and relative humidity (40-70\%) were controlled using an air conditioner. The corona needle used as the point electrode was a headless stainless steel pin (Shiga, Tokyo, Japan) with a diameter of $200 \mu \mathrm{m}, 20 \mathrm{~mm}$ in length. The needle tip had a radius of curvature of $c a .1 \mu \mathrm{m}$ and the shape of the needle tip surface was adequately approximated by a hyperboloid of revolution. The opposite electrode was the stainless steel orifice plate of a TSQ-7000 triple-quadrupole mass spectrometer (Thermo Fisher Scientific, San Jose, CA, USA). The discharge gap between the electrodes was adjusted to $3 \mathrm{~mm}$ using a manipulator. The DC corona voltage and needle angle with respect to the orifice hole axis used were $-1.9 \mathrm{kV}$ and $\pi / 2 \mathrm{rad}$., respectively. A ceramic micro-heater was placed between the needle and the orifice plate in order to vaporize condensed-phase analytes. Analytes diffused into the discharge area and were negatively ionized. The resulting gas-phase analyte ions were introduced into the orifice hole of the mass spectrometer. The collision gas and energy (lab.) used in the CID experiments were argon at $2.0 \times 10^{-3}$ Torr and 5 $-40 \mathrm{eV}$, respectively.

\section{RESULTS AND DISCUSSION}

\section{Collision-induced dissociation of adduct ions $[\mathbf{M}+\mathbf{R}]^{-}$}

The corona voltage and needle angle used led to a low electric field strength on the needle tip surface $\left(\approx 10^{7} \mathrm{~V} \mathrm{~m}^{-1}\right)$ and resulting $\mathrm{NO}_{3}^{-}$-free discharge area. ${ }^{21)}$ As previously reported, ${ }^{21)}$ an $\mathrm{NO}_{3}^{-}$-free area can bring about the predominant formation of atmospheric negative ions $\mathrm{R}^{-}$with relatively high proton affinities (PAs), including $\mathrm{O}_{2}^{-}$ $\left(\mathrm{PA}\left(\mathrm{O}_{2}^{-}\right)=-\Delta H^{\circ}\left(\mathrm{O}_{2}^{-}+\mathrm{H}^{+} \rightarrow \mathrm{HO}_{2}\right)=1477.0 \pm 2.9 \mathrm{~kJ} \mathrm{~mol}^{-1}\right),{ }^{22)} \mathrm{HCO}_{3}^{-}$ $\left(\mathrm{PA}\left(\mathrm{HCO}_{3}^{-}\right)<1551.0 \pm 9.2 \mathrm{~kJ} \mathrm{~mol}^{-1}\right),{ }^{23)}$ and $\mathrm{NO}_{2}^{-}\left(\mathrm{PA}\left(\mathrm{NO}_{2}^{-}\right)=\right.$ $\left.1423.4 \pm 9.2 \mathrm{~kJ} \mathrm{~mol}^{-1}\right){ }^{24)}$ Figure 1 shows that those $\mathrm{R}^{-}$ions ionize analytes $\mathrm{M}$ such as L-phenylalanine (Phe), L-homophenylalanine (HPA), and L-phenylglycine (PG) to form adducts $[\mathrm{M}+\mathrm{R}]^{-}$. The $[\mathrm{M}+\mathrm{R}]^{-}$ions can be produced via the following three-body reactions with a third body $P$ such as $\mathrm{N}_{2}$ or $\mathrm{O}_{2}$ in the discharge area. ${ }^{7)}$

$$
\mathrm{M}+\mathrm{R}^{-}+P \rightarrow[\mathrm{M}+\mathrm{R}]^{-}+P \quad\left(P: \mathrm{N}_{2}, \mathrm{O}_{2}\right)
$$

It has been reported that CID experiments on the adducts $[\mathrm{M}+\mathrm{R}]^{-}$formed in an $\mathrm{NO}_{3}^{-}$-free area make it possible to analyze the fragmentation behavior of deprotonated analytes
$[\mathrm{M}-\mathrm{H}]^{-} .{ }^{25)}$ That is, the $[\mathrm{M}+\mathrm{R}]^{-}$ions initially dissociate, accompanied by proton abstraction from $\mathrm{M}$ by $\mathrm{R}^{-}$due to the higher proton affinity of $\mathrm{R}^{-} v s$. M, resulting in the generation of $[\mathrm{M}-\mathrm{H}]^{-}$(Reaction 2).

$$
[\mathrm{M}+\mathrm{R}]^{-} \rightarrow[\mathrm{M}-\mathrm{H}]^{-}+\mathrm{RH}
$$

The $[\mathrm{M}-\mathrm{H}]^{-}$product ions formed via Reaction 2 have the same structure as $[\mathrm{M}-\mathrm{H}]^{-}$ions generated in an APCDI source. When the $[\mathrm{M}-\mathrm{H}]^{-}$product ions have excess energy, further fragmentation of $[\mathrm{M}-\mathrm{H}]^{-}$can occur. The fragmentation behavior of $[\mathrm{M}+\mathrm{R}]^{-}$adducts formed in an $\mathrm{NO}_{3}^{-}$-free area has been described in detail elsewhere. ${ }^{25,26)}$

Figures 2-4 show the CID spectra of the adduct ions $[\mathrm{M}+\mathrm{R}]^{-}\left(\mathrm{R}^{-}: \mathrm{O}_{2}^{-}, \mathrm{HCO}_{3}^{-}\right.$, and $\left.\mathrm{NO}_{2}^{-}\right)$for Phe, HPA, and PG, respectively, obtained at a collision energy of $25 \mathrm{eV}$. The CID of $[\mathrm{Phe}+\mathrm{R}]^{-},[\mathrm{HPA}+\mathrm{R}]^{-}$, and $[\mathrm{PG}+\mathrm{R}]^{-}$resulted in the formation of individual deprotonated analytes $[\mathrm{M}-\mathrm{H}]^{-}$as well as the product ions at $m / z$ 147, 103, 91, and 72 ( $\nabla$ in Figs. 2(a)-(c)), 91 and 74 ( $\nabla$ in Figs. 3(a)-(c)), and 106 ( $\nabla$ in Figs. 4(a)-(c)), respectively. According to a previous study, ${ }^{25)}$ the product ions marked as $\nabla$ in Figs. 2-4 most likely originate from the deprotonated analytes $[\mathrm{M}-\mathrm{H}]^{-}$. Other studies using ESI tandem MS and fast atom bombardment collisional activation MS have also reported the generation of product ions at $m / z 147,103,91$, and 72 in the CID of $[\mathrm{Phe}-\mathrm{H}]^{-12,14)}$ which is consistent with the present results (Fig. 2). On the basis of the CID spectra of the adduct ions $[\mathrm{M}+\mathrm{R}]^{-}$for Phe, HPA, and $\mathrm{PG}$ obtained here, the fragmentation behavior of the deprotonated analytes $[\mathrm{Phe}-\mathrm{H}]^{-},[\mathrm{HPA}-\mathrm{H}]^{-}$, and $[\mathrm{PG}-\mathrm{H}]^{-}$are discussed below.

\section{Fragmentation characteristics of $[\mathrm{M}-\mathrm{H}]^{-}$}

The $[\mathrm{Phe}-\mathrm{H}]^{-}$at $\mathrm{m} / z 164$ fragments to form the product ions at $m / z 147,103,91$, and 72, as shown in Fig. 2. The abundances of those product ions varies with varying collision energy. Figure 5(a) shows the relative intensities of $[\mathrm{Phe}-\mathrm{H}]^{-}$ and the resulting four product ions as a function of collision energy, obtained from the CID spectra of the $\mathrm{O}_{2}^{-}$adducts $\left[\mathrm{Phe}+\mathrm{O}_{2}\right]^{-}$. The relative intensities $(R I)$ of individual ions at a given collision energy were calculated from the measured absolute peak intensities $A I\left(\mathrm{Y}^{-}\right)\left(\mathrm{Y}^{-} \text {: }\left[\mathrm{Phe}+\mathrm{O}_{2}\right]^{-} \text {, [Phe- } \mathrm{H}\right]^{-}$, and product ions at $\mathrm{m} / \mathrm{z} 147,103,91$, and 72 ) in the CID spectra using the following equation:

$$
R I\left(\mathrm{Y}^{-}\right)=\left(A I\left(\mathrm{Y}^{-}\right)\right) / \sum\left(A I\left(\mathrm{Y}^{-}\right)\right) \times 100
$$

The intensity patterns of individual ions with changing collision energy are independent of the atmospheric ion species $\mathrm{R}^{-}$of the precursor ions $[\mathrm{Phe}+\mathrm{R}]^{-}$. At low collision energies $(10-20 \mathrm{eV})$, the product ion at $\mathrm{m} / \mathrm{z} 147$ is dominant, likely formed via the loss of $\mathrm{NH}_{3}(17 \mathrm{Da})$ from $[\mathrm{Phe}-\mathrm{H}]^{-}$. With increasing collision energy, the relative intensity of the product ion at $\mathrm{m} / z 103$ increases while the ion at $\mathrm{m} / z 147 \mathrm{de}$ creases. This result suggests that the product ion at $\mathrm{m} / \mathrm{z} 147$ having excess internal energy can be further fragmented via the loss of $\mathrm{CO}_{2}(44 \mathrm{Da})$ to form the product ion at $\mathrm{m} / \mathrm{z} 103$. In order to understand the detailed fragmentation behavior of [Phe- $\mathrm{H}]^{-}$to form the product ions at $\mathrm{m} / z 147$ and 103, CID experiments using an isotope-labeled analyte, Phe- $d_{2}$, having two deuterium (D) atoms at the benzyl position (see Fig. $1(\mathrm{~b})$ ), were performed. The CID spectrum of $\left[\mathrm{Phe}-d_{2}+\mathrm{O}_{2}\right]^{-}$at $\mathrm{m} / z 199$ obtained at a collision energy of $25 \mathrm{eV}$ is shown in Fig. 2(d). The product ions at $m / z 148$ and 104 are shifted by 
( a )<smiles>NC(Cc1ccccc1)C(=O)O</smiles>

L-phenylalanine $\left(M_{r} 165\right)$

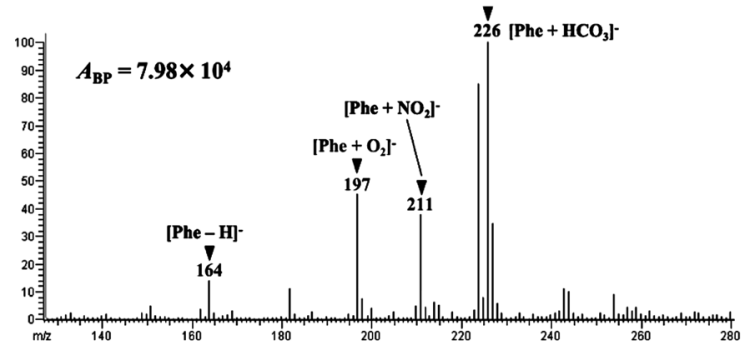

( b )<smiles>[2H]C([2H])(c1ccccc1)C(N)C(=O)O</smiles>

deuterium labeled derivative of L-phenylalanine $\left(M_{r}\right.$ 167)

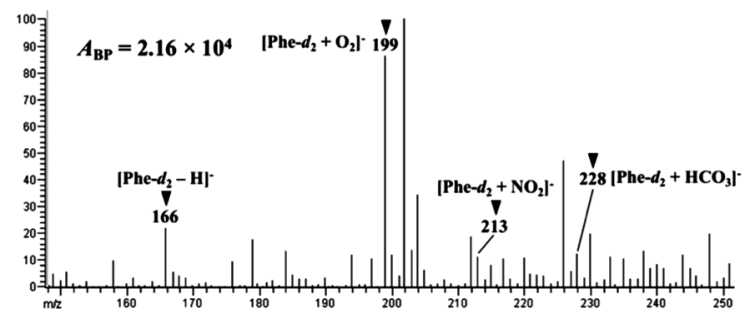

(c)<smiles>NC(CCc1ccccc1)C(=O)O</smiles>

L-homophenylalanine $\left(M_{r} 179\right)$

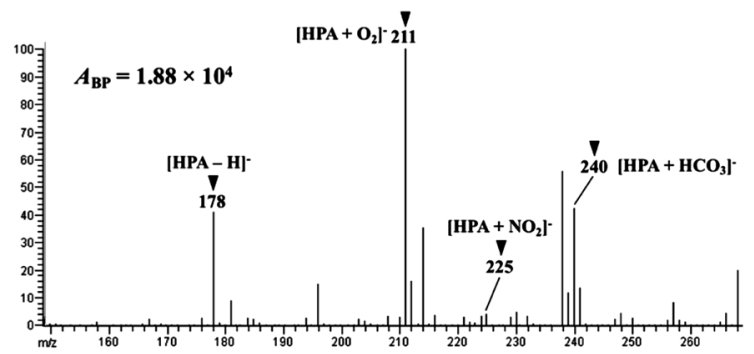

(d)<smiles>NC(C(=O)O)c1ccccc1</smiles>

L-phenylglycine $\left(M_{r}\right.$ 151)

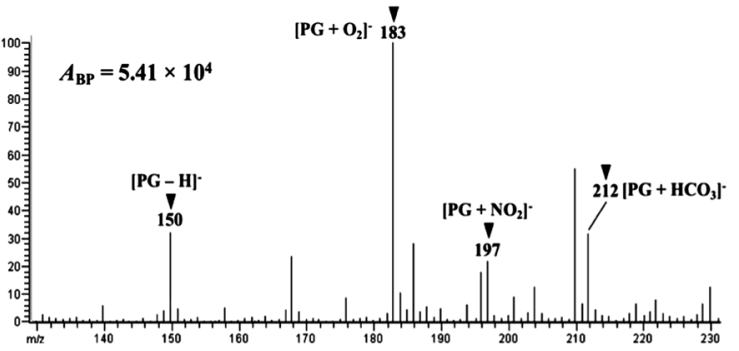

Fig. 1. Negative ion mass spectra of (a) Phe, (b) Phe- $d_{2}$, (c) HPA, and (d) PG. $A_{\mathrm{BP}}$ represents the absolute abundance (arbitrary units) of the base peak in each mass spectrum.
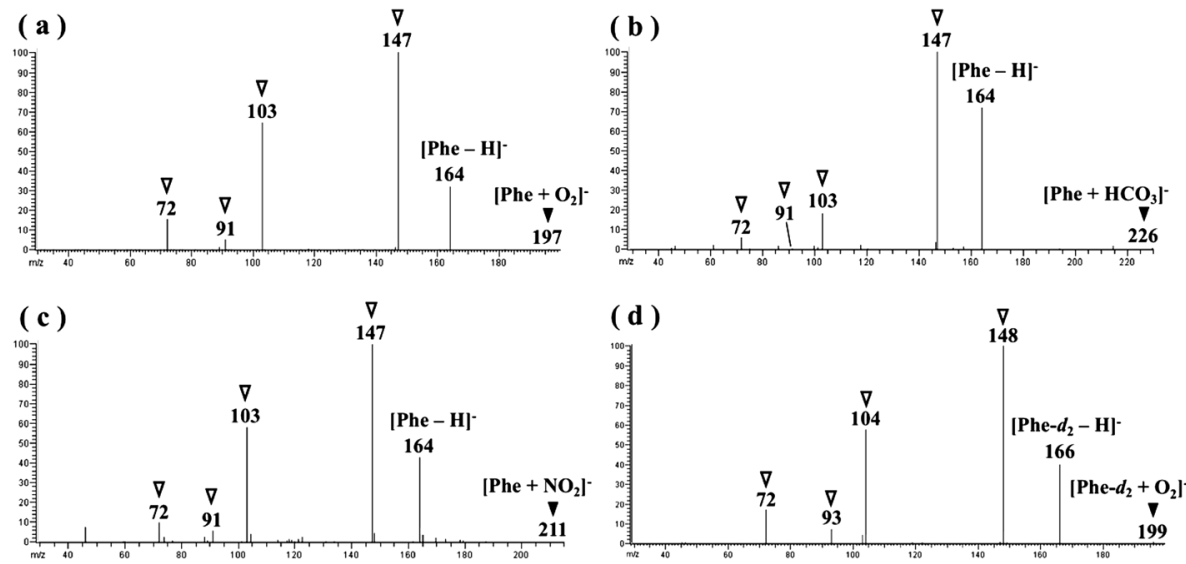

Fig. 2. APCDI-CID spectra of the precursor ions (a) $\left[\mathrm{Phe}+\mathrm{O}_{2}\right]^{-}$, (b) $\left[\mathrm{Phe}+\mathrm{HCO}_{3}\right]^{-}$, (c) $\left[\mathrm{Phe}+\mathrm{NO}_{2}\right]^{-}$, and (d) $\left[\mathrm{Phe}-d_{2}+\mathrm{O}_{2}\right]^{-}$obtained at a collision energy of $25 \mathrm{eV}$. 


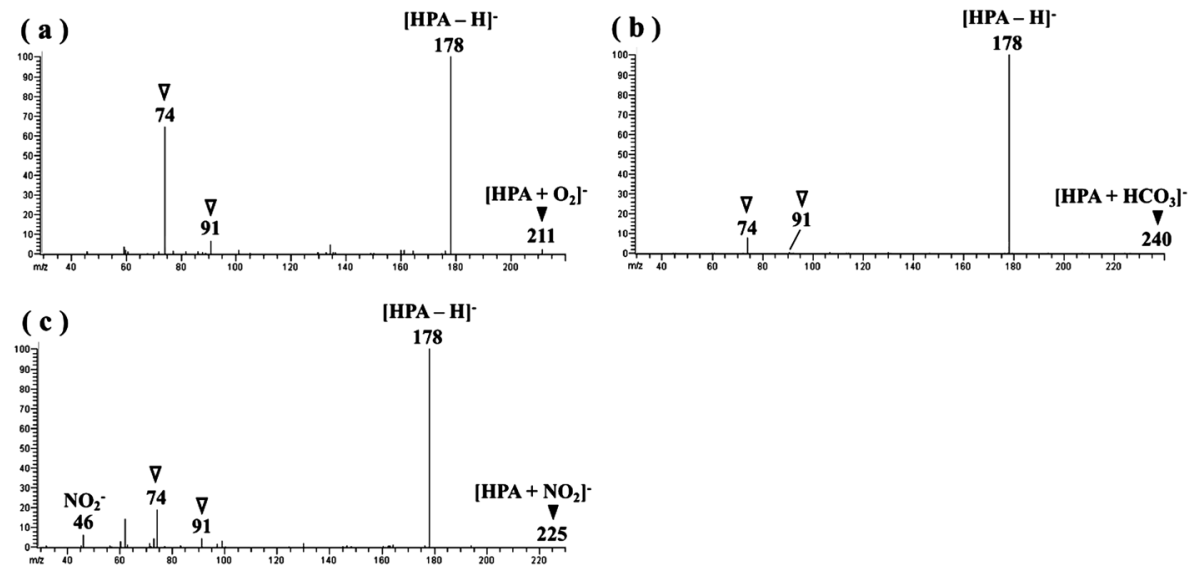

Fig. 3. APCDI-CID spectra of the precursor ions (a) $\left[\mathrm{HPA}+\mathrm{O}_{2}\right]^{-}$, (b) $\left[\mathrm{HPA}+\mathrm{HCO}_{3}\right]^{-}$, and (c) $\left[\mathrm{HPA}+\mathrm{NO}_{2}\right]^{-}$obtained at a collision energy of $25 \mathrm{eV}$.
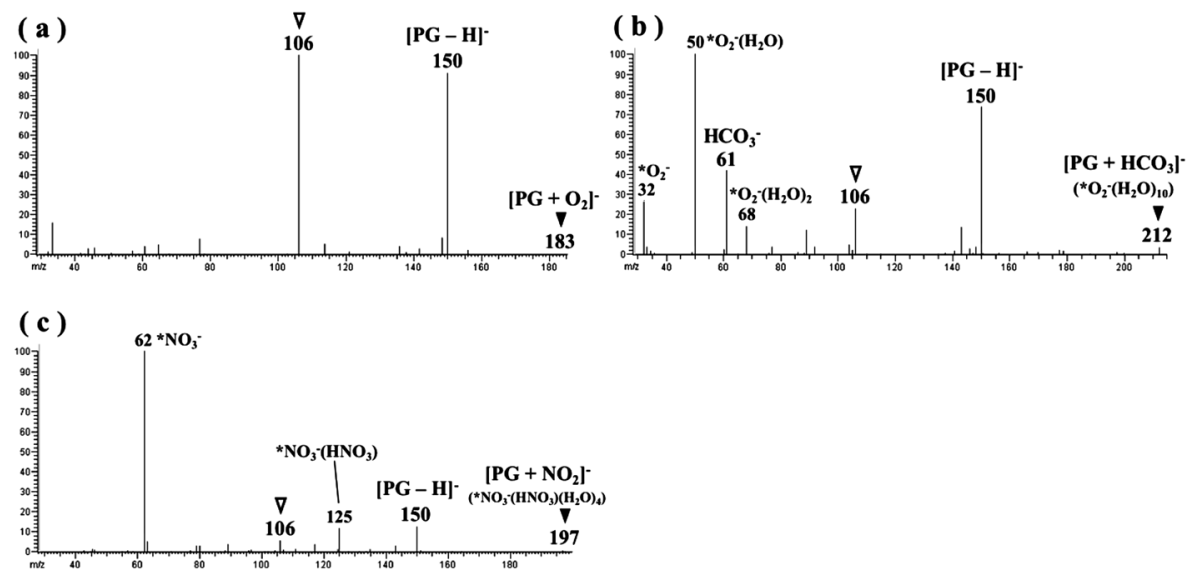

Fig. 4. APCDI-CID spectra of the precursor ions (a) $\left[\mathrm{PG}+\mathrm{O}_{2}\right]^{-}$, (b) $\left[\mathrm{PG}+\mathrm{HCO}_{3}\right]^{-}$, and (c) $\left[\mathrm{PG}+\mathrm{NO}_{2}\right]^{-}$obtained at a collision energy of $25 \mathrm{eV}$. The ion peaks having an asterisk $\left(^{*}\right)$ represent the atmospheric ions as background.

$1 \mathrm{Da}$ relative to the ions produced via the CID of $[\mathrm{Phe}+\mathrm{R}]^{-}$ $(\mathrm{m} / z 147$ and 103 in Figs. 2(a)-(c)). This fact indicates that both of the product ions at $\mathrm{m} / z 148$ and 104 contain one $\mathrm{D}$ atom, i.e., $[\mathrm{Phe}-\mathrm{H}]^{-}$initially loses the amino group and one $\mathrm{H}$ atom from the benzylic position to form the product ion at $\mathrm{m} / \mathrm{z} 147$. This phenomenon can occur due to the rearrangement of a proton from the benzylic position to a carboxyl group via a five-membered ring transition state, resulting in the formation of an intermediate which possesses a carbanion at the benzyl position. Thus, the fragmentation pathway of $[\mathrm{Phe}-\mathrm{H}]^{-}$to form the product ions at $\mathrm{m} / \mathrm{z} 147$ and 103 can be presumed to be as shown in Scheme 1(a).

The $[\mathrm{Phe}-\mathrm{H}]^{-}$ion activated at higher collision energy led to the formation of product ions at $m / z 91$ and 72 (Fig. $5(\mathrm{a}))$. It should be noted that CID of $\left[\mathrm{Phe}-d_{2}-\mathrm{H}\right]^{-}$resulted in product ions at $m / z 93$ and 72, suggesting that they contain two and no D atoms, respectively. It is likely therefore that the product ion at $m / z 91$ corresponds to a benzyl anion (BA) originating from the side-chain of $[\mathrm{Phe}-\mathrm{H}]^{-}$, while the ion at $\mathrm{m} / \mathrm{z} 72$ is attributable to the backbone moiety. In order to explain the formation of the product ions at $\mathrm{m} / \mathrm{z}$ 91 and 72 , it is reasonable to propose that $[\mathrm{Phe}-\mathrm{H}]^{-}$can be converted into an ion-neutral complex consisting of BA and iminoglycine (IG, $73 \mathrm{Da}$ ) via rearrangement of a proton from the amino group to the carboxyl group through a five- membered ring transition state, as shown in Scheme 1(b)-i. When the ion-neutral complex simply dissociates into BA and IG, the BA can be produced as the product ion at $\mathrm{m} / \mathrm{z}$ 91 (Scheme 1(b)-ii). In contrast, it could be expected that the ion-neutral complex dissociates accompanied by proton abstraction from IG by BA, because of the high proton affinity of BA $\left(1587 \pm 8.8 \mathrm{~kJ} \mathrm{~mol}^{-1}\right){ }^{27}$ ) This process leads to the formation of deprotonated IG, $[\mathrm{IG}-\mathrm{H}]^{-}$, at $\mathrm{m} / z 72$ as an alternate product ion (Scheme 1(b)-iii). The formation of $[\mathrm{IG}-\mathrm{H}]^{-}(\mathrm{m} / \mathrm{z} 72)$ dominates as compared to that of BA $(\mathrm{m} / \mathrm{z}$ 91) with increasing collision energy, as shown in Fig. 5. This result may indicate that the activation energy for the dissociation reaction accompanied by proton transfer from IG to BA (Scheme 1(b)-iii) is higher than that for the simple dissociation into BA and IG (Scheme 1(b)-ii). Figure 5(a) also shows that the reactions presented in Scheme 1(a) can begin to occur at lower collision energy than those in Scheme 1(b), while both Schemes 1(a) and (b) originate from proton rearrangement via transition states and intermediates including carbanions at the benzyl position. This can be interpreted by energy values related to proton release from the benzyl position and the amino group in $[\mathrm{Phe}-\mathrm{H}]^{-}$, estimated approximately using the gas-phase acidities (GAs) of toluene $\left(\mathrm{C}_{6} \mathrm{H}_{5} \mathrm{CH}_{3}\right)$ and ethylamine $\left(\mathrm{C}_{2} \mathrm{H}_{5} \mathrm{NH}_{2}\right)$. The GA of toluene $\left(\Delta H^{\circ}\left(\mathrm{C}_{6} \mathrm{H}_{5} \mathrm{CH}_{3} \rightarrow \mathrm{C}_{6} \mathrm{H}_{5} \mathrm{CH}_{2}^{-}(\mathrm{BA})+\mathrm{H}^{+}\right)\right), 1587 \pm 8.8,{ }^{27)}$ is lower 
(a)

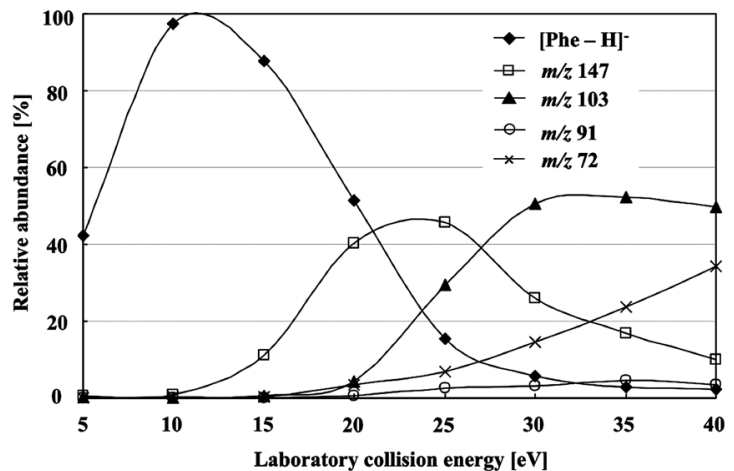

(b)

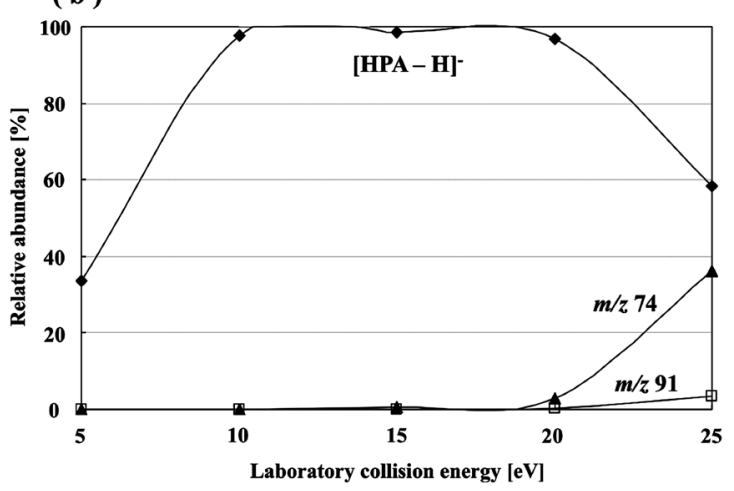

(c)

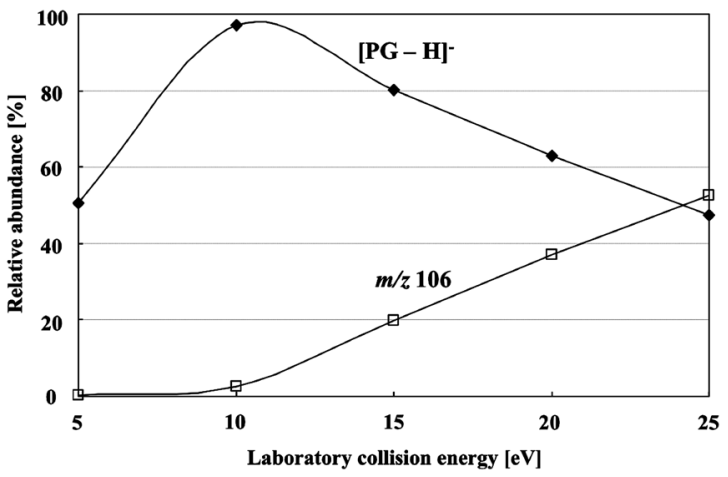

Fig. 5. Relative intensities of (a) $[\mathrm{Phe}-\mathrm{H}]^{-}$and the product ions at $\mathrm{m} / z$ 147, 103, 91, and 72, (b) [HPA-H] ${ }^{-}$and the product ions at $\mathrm{m} / z$ 91 and 74, and (c) [PG-H] $]^{-}$and the product ion at $\mathrm{m} / \mathrm{z}$ 106 as a function of collision energy, obtained using the CID spectra of $\left[\mathrm{M}+\mathrm{O}_{2}\right]^{-}$for individual analytes $\mathrm{M}$.

than that of ethylamine $\left(\Delta H^{\circ}\left(\mathrm{C}_{2} \mathrm{H}_{5} \mathrm{NH}_{2} \rightarrow \mathrm{C}_{2} \mathrm{H}_{5} \mathrm{NH}+\mathrm{H}^{+}\right)\right)$, $1671 \pm 4.6 \mathrm{~kJ} \mathrm{~mol}^{-1}{ }^{28)}$ It is therefore suggested that a proton at the benzyl position can be released under less energetic conditions as compared to one at the amino group in $[\mathrm{Phe}-\mathrm{H}]^{-}$, resulting in the occurrence of reactions originating from proton rearrangement from the benzyl position (Scheme 1(a)) at lower collision energy.

Collision-induced dissociation of $[\mathrm{HPA}-\mathrm{H}]^{-}$ions $(\mathrm{m} / \mathrm{z}$ 178) led to the formation of product ions at $\mathrm{m} / \mathrm{z} 74$ and 91 (Fig. 3), which most likely correspond to the glycine enolate and benzyl anions originating from the backbone and sidechains of $[\mathrm{HPA}-\mathrm{H}]^{-}$, respectively. Taking into account the fragmentation behavior of $[\mathrm{Phe}-\mathrm{H}]^{-}$shown in Scheme 1(a), it seems likely that the glycine enolate anion $(\mathrm{m} / z 74)$ occurs via initial proton rearrangement from the benzyl position to the carboxyl group through a six-membered ring transition state, followed by subsequent loss of styrene (104 Da) from $[\mathrm{HPA}-\mathrm{H}]^{-}$, as shown in Scheme 2(a). The benzyl anion at $\mathrm{m} / \mathrm{z} 91$ is likely formed via simple dissociation reactions including the successive loss of $\mathrm{CO}_{2}(44 \mathrm{Da})$ and ethenamine (43 Da) (Scheme 2(b)). The dominant formation of the glycine enolate anion at $\mathrm{m} / \mathrm{z} 74$, independent of precursor ion species and collision energy (Figs. 3 and 5(b)), indicates that preferential proton rearrangement via the six-membered ring transition state (Scheme 2(a)) takes place as compared to the simple dissociation reaction (Scheme 2(b)). In contrast, the $[\mathrm{PG}-\mathrm{H}]^{-}$ion at $\mathrm{m} / z 150$ can only be fragmented to form the product ion at $\mathrm{m} / z 106$ via the loss of $\mathrm{CO}_{2}$, regardless of collision energy (Fig. 5(c)). A proposed fragmentation mechanism for $[\mathrm{PG}-\mathrm{H}]^{-}$is shown in Scheme 3.

It should be noted here that all of the fragmentations observed in the CID of $[\mathrm{Phe}-\mathrm{H}]^{-}$, [HPA-H] $]^{-}$, and $[\mathrm{PG}-\mathrm{H}]^{-}$involve intermediates and/or product ions which include carbanions at the benzyl position (Schemes 1-3). The carbanions are most likely stabilized by resonance. ${ }^{6)}$ It is therefore concluded that the principal factor governing the fragmentation characteristics of deprotonated Phe homologues is the stability of the structure of intermediates and/or product ions. That is, fragmentations proceed to form benzyl carbanions having resonance-stabilized structures via proton rearrangement through transition states and/or simple dissociation reactions.

\section{CONCLUSION}

The fragmentation behavior of deprotonated L-phenylalanine (Phe) and its homologues L-homophenylalanine (HPA) and L-phenylglycine (PG) was investigated using CID-MS combined with $\mathrm{NO}_{3}^{-}$-free APCDI. Analytes $\mathrm{M}$ in the $\mathrm{NO}_{3}^{-}$free discharge area were ionized by atmospheric negative ions $\mathrm{R}^{-}$having high proton affinities, e.g., $\mathrm{O}_{2}^{-}, \mathrm{HCO}_{3}^{-}$, and $\mathrm{NO}_{2}^{-}$, to form $[\mathrm{M}+\mathrm{R}]^{-}$adducts. The CID of individual adducts $[\mathrm{M}+\mathrm{R}]^{-}$led to the formation of product ions originating from deprotonated analytes $[\mathrm{M}-\mathrm{H}]^{-}$. The observed fragmentation behavior of $[\mathrm{Phe}-\mathrm{H}]^{-},[\mathrm{HPA}-\mathrm{H}]^{-}$, and $[\mathrm{PG}-\mathrm{H}]^{-}$ lead to the following conclusions:

1. The principal factor governing the fragmentation behavior of the deprotonated Phe homologues $[\mathrm{M}-\mathrm{H}]^{-}$is the stability of the structure of intermediates and/or product ions. That is, all of the precursor ions $[\mathrm{M}-\mathrm{H}]^{-}$ dissociate to form a carbanion at the benzyl position, having a resonance-stabilized structure, via proton rearrangement through a transition state and/or via simple dissociation reactions.

2. If a given precursor ion $[\mathrm{M}-\mathrm{H}]^{-}$is capable of generating a benzyl carbanion via both proton rearrangement and a simple dissociation reaction, the proton rearrangement proceeds preferentially as compared to the simple dissociation reactions.

3. If there are some different proton rearrangement pathways generating benzyl carbanions in the CID of a certain $[\mathrm{M}-\mathrm{H}]^{-}$ion, the pathway originating from the position at which a proton can be released less energetically proceeds under lower collision energy conditions.

The present study contributes to an understanding of the fragmentation behavior of deprotonated aromatic amino 


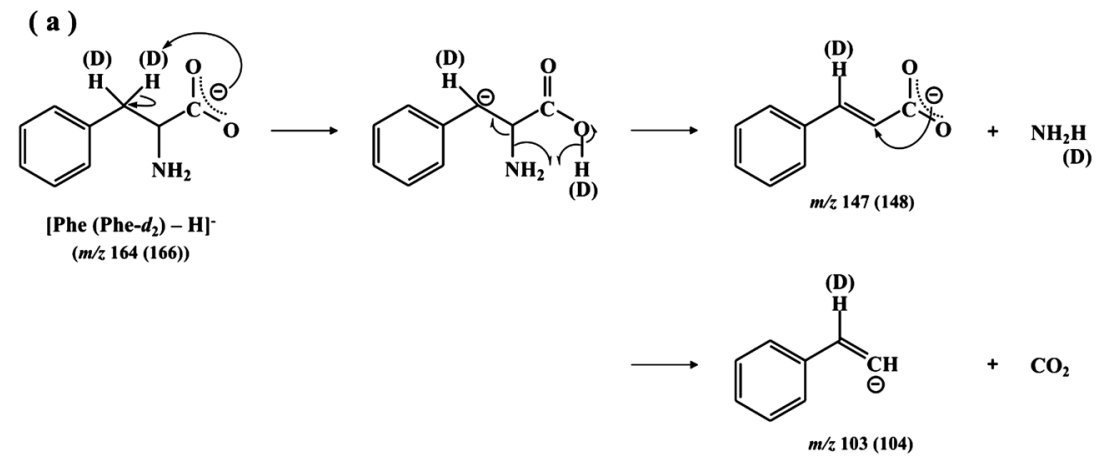

(b)

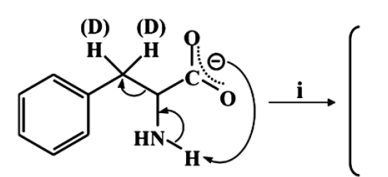

[Phe (Phe- $\left.\left.d_{2}\right)-H\right]^{-}$ $(m / z 164$ (166))

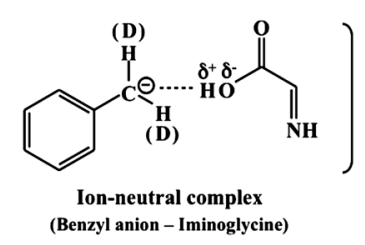

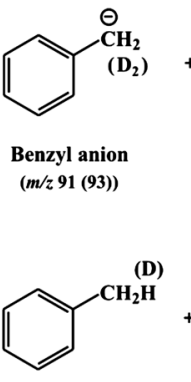

Toluene

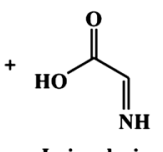

minoglycine (IG)

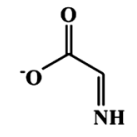

$\left[\right.$ IG $-\mathrm{H}^{-}$

Scheme 1. Proposed fragmentation behavior of deprotonated (D labeled) L-phenylalanine [Phe (Phe- $\left.\left.d_{2}\right)-\mathrm{H}\right]^{-}$to form (a) the product ions at $m / z$ 147 (148) and 103 (104) and (b) $\mathrm{m} / z 91$ (93) and 72.

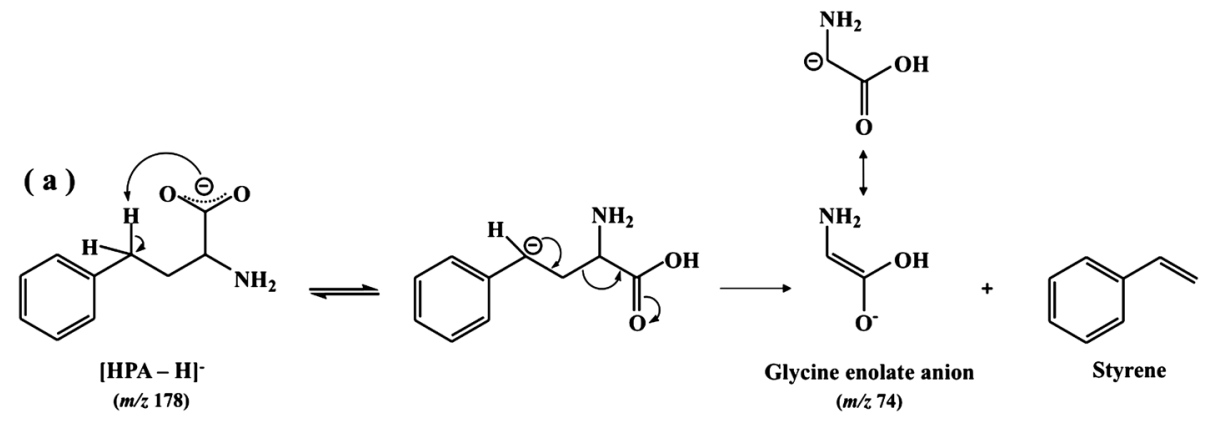

( b )

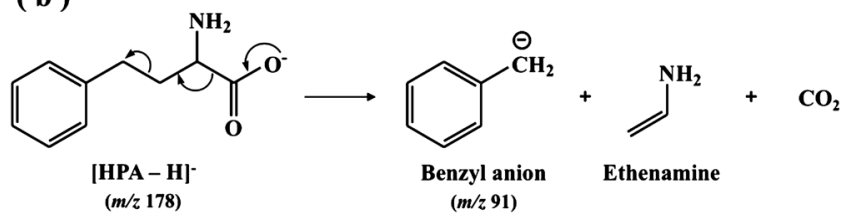

Scheme 2. Proposed fragmentation behavior of deprotonated L-homophenylalanine [HPA-H] $]^{-}$to form (a) the product ions at $m / z 74$ and (b) $m / z 91$.

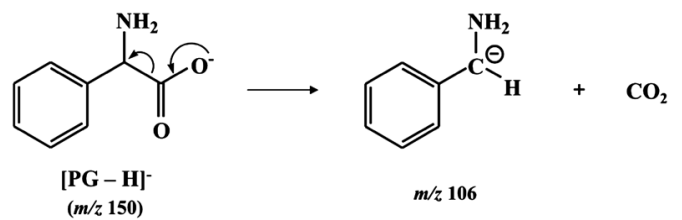

Scheme 3. Proposed fragmentation behavior of deprotonated Lphenylglycine $[\mathrm{PG}-\mathrm{H}]^{-}$to form a benzyl carbanion at $\mathrm{m} / \mathrm{z}$ 106. acids.

\section{Acknowledgements}

This work was supported by Grants-in-Aid for Scientific Research (C) (23550101 and 24619005) from the Ministry of Education, Culture, Sports, Science and Technology in Japan. The authors thank Dr. Hisao Nakata, Professor emeritus at the Aichi University of Education, for insightful comments and helpful discussion. 


\section{REFERENCES}

1) G. Sarwar, H. G. Botting. Evaluation of liquid chromatographic analysis of nutritionally important amino acids in food and physiological samples. J. Chromatogr. B Analyt. Technol. Biomed. Life Sci. 615: 1-22, 1993.

2) D. Fekkes. State-of-the-art of high-performance liquid chromatographic analysis of amino acids in physiological samples. J. Chromatogr. B Analyt. Technol. Biomed. Life Sci. 682: 3-22, 1996.

3) D. H. Spackman, W. H. Stein, S. Moore. Automatic recording apparatus for use in chromatography of amino acids. Anal. Chem. 30: 1190-1206, 1958.

4) K. Biemann, J. A. McCloskey. Mass spectra of organic molecules. II. Amino acids. J. Am. Chem. Soc. 84: 3192-3193, 1962.

5) G. Junk, H. Svec. The mass spectra of $\alpha$-amino acids. J. Am. Chem. Soc. 85: 839-845, 1963.

6) H. U. Winkler, H. D. Beckey. Field desorption mass spectrometry of amino acids. Org. Mass Spectrom. 6: 655-660, 1972.

7) G. W. A. Milne, T. Axenrod, H. M. Fales. Chemical ionization mass spectrometry of complex molecules. IV. Amino acids. J. Am. Chem. Soc. 92: 5170-5175, 1970.

8) M. Meot-Ner, F. H. Field. Chemical ionization mass spectrometry. XX. Energy effects and virtual ion temperature in the decomposition kinetics of amino acids and amino acid derivatives. J. Am. Chem. Soc. 95: 7207-7211, 1973.

9) C. W. Tsang, A. G. Harrison. Chemical ionization of amino acids. J. Am. Chem. Soc. 98: 1301-1308, 1976.

10) D. Voigt, J. Schmidt. Negative ion mass spectroscopy of natural products. VIII- $\alpha$-Amino acids. Biomed. Mass Spectrom. 5: 44-46, 1978.

11) A. G. Netting, A. M. Duffield. Positive and negative ion methane chemical ionization mass spectrometry of amino acid pentafluorobenzyl derivatives. Biomed. Mass Spectrom. 12: 668-672, 1985.

12) W. Kulik, W. Heerma. A study of the positive and negative ion fast atom bombardment mass spectra of $\alpha$-amino acids. Biomed. Environ. Mass Spectrom. 15: 419-427, 1988.

13) M. Eckersley, J. H. Bowie, R. N. Hayes. Collision-induced dissociations of deprotonated $\alpha$-amino acids. The occurrence of specific proton transfers preceding fragmentation. Int. J. Mass Spectrom. Ion Process. 93: 199-213, 1989.

14) M. Piraud, C. Vianey-Saban, K. Petritis, C. Elfakir, J.-P. Steghens, A. Morla, D. Bouchu. ESI-MS/MS analysis of underivatised amino acids: A new tool for the diagnostic of inherited disorders of amino acid metabolism. Fragmentation study of 79 molecules of biological interest in positive and negative ionization mode. Rapid Commun. Mass Spectrom. 17: 1297-1311, 2003.

15) T. Soga, D. N. Heiger. Amino acid analysis by capillary electro- phoresis electrospray ionization mass spectrometry. Anal. Chem. 72: 1236-1241, 2000.

16) J. Qu, W. Chen, G. Luo, Y. Wang, S. Xiao, Z. Ling, G. Chen. Rapid determination of underivatized pyroglutamic acid, glutamic acid glutamine and other relevant amino acids in fermentation media by LC-MS-MS. Analyst (Lond.) 127: 66-69, 2002.

17) K. Petritis, P. Chaimbault, C. Elfakir, M. Dreux. Parameter optimization for the analysis of underivatized protein amino acids by liquid chromatography and ionspray tandem mass spectrometry. J. Chromatogr. A 896: 253-263, 2000.

18) A. Martin-Girardeau, M.-F. Renou-Gonnord. Optimization of a capillary electrophoresis-electrospray mass spectrometry method for the quantitation of the 20 natural amino acids in childrens blood. J. Chromatogr. B Analyt. Technol. Biomed. Life Sci. 742: $163-171,2000$

19) S. Özcan, H. Z. Senyuva. Improved and simplified liquid chromatography/atmospheric pressure chemical ionization mass spectrometry method for the analysis of underivatized free amino acids in various foods. J. Chromatogr. A 1135: 179-185, 2006.

20) S.-S. Choi, O.-B. Kim. Fragmentation of deprotonated amino acids in atmospheric pressure chemical ionization. Int. J. Mass Spectrom. 338: 17-22, 2013.

21) K. Sekimoto, M. Sakai, M. Takayama. Specific interaction between negative atmospheric ions and organic compounds in atmospheric pressure corona discharge ionization mass spectrometry. J. Am. Soc. Mass Spectrom. 23: 1109-1119, 2012.

22) M. J. Travers, D. C. Cowles, G. B. Ellison. Reinvestigation of the electron affinities of $\mathrm{O}_{2}$ and NO. Chem. Phys. Lett. 164: 449-455, 1989.

23) J. H. Bowie, C. H. Depuy, S. A. Sullivan, V. M. Bierbaum. Gasphase reactions of the hydroperoxide and peroxyformate anions. Can. J. Chem. 64: 1046-1050, 1986.

24) K. M. Ervin, J. Ho, W. C. Lineberger. Ultraviolet photoelectron spectrum of nitrate anion. J. Phys. Chem. 92: 5405-5412, 1988.

25) K. Sekimoto, N. Matsuda, M. Takayama. Collision-induced dissociation study of the adduct ions produced in $\mathrm{NO}_{3}^{-}$-free area of atmospheric pressure negative corona discharges under ambient air conditions. Mass Spectrom. 2: A0020, 2013.

26) K. Sekimoto, M. Takayama. Collision-induced dissociation analysis of negative atmospheric ion adducts in atmospheric pressure corona discharge ionization mass spectrometry. J. Am. Soc. Mass Spectrom. 24: 780-788, 2013.

27) J.-F. Gal, M. Decouzon, P.-C. Maria, A. I. González, O. Mó, M. Yáñez, S. E. Chaouch, J.-C. Guillemin. Acidity trends in $\alpha, \beta$ unsaturated alkanes, silanes, germans, and stannanes. J. Am. Chem. Soc. 123: 6353-6359, 2001.

28) G. J. MacKay, R. S. Hemsworth, D. K. Bohme. Absolute gas-phase acidities of $\mathrm{CH}_{3} \mathrm{NH}_{2}, \mathrm{C}_{2} \mathrm{H}_{5} \mathrm{NH}_{2},\left(\mathrm{CH}_{3}\right)_{2} \mathrm{NH}$ and $\left(\mathrm{CH}_{3}\right)_{3} \mathrm{~N}$. Can. J. Chem. 54: 1624-1642, 1976. 